\title{
Bilateral paraganglioma
}

\author{
Rushikesh Yogesh Trivedi, Samuel C Leong \\ Department of Otorhino-laryngology - Head and Neck Surgery, Aintree University Hospital, Liverpool, Merseyside, UK
}

Correspondence to: Dr Samuel C Leong, Icheel@doctors.org.uk

\section{Summary}

A 41-year-old man presented with bilateral, painless, non-pulsatile left-sided neck swelling. This was noticed incidentally on a routine medical check-up. He had no significant medical history and did not take any regular medications. Urinary catecholamines and routine blood tests were all normal, and when he had been examined he was normotensive. The MRI scan revealed an enhancing lesion on the left side of the neck as seen in figure 1; it measured $4 \mathrm{~cm} \times 3 \mathrm{~cm}$ and had a 'salt and pepper' appearance causing splaying of the internal and external carotid arteries at the level of the bulb. There was a similar enhancing lesion on the right side, measuring $2.6 \mathrm{~cm} \times 2 \mathrm{~cm}$ at the level of the carotid bifurcation and $5 \mathrm{~cm} \times 2.6 \mathrm{~cm}$ at the jugular bulb, this is seen in figure 1 . A diagnosis of bilateral paraganglioma was made.

\section{BACKGROUND}

This is an important case as it is a rare condition when occurring bilaterally that is relatively easily diagnosed by a good history and clinical examination, using MRI scanning as an aid to diagnosis and follow-up.

\section{CASE PRESENTATION}

A 41-year-old man presented with bilateral, painless, nonpulsatile left-sided neck swelling (figure 1). This was noticed incidentally on a routine medical check-up. He had no significant medical history and did not take any regular medications.

\section{DISCUSSION}

The described patient has bilateral paragangliomas. A detailed history was taken from the patient mentioned, paying particular attention to the family history. In this case, sporadic paraganglioma seemed the most plausible diagnosis.

Paragangliomas are neuro-endocrine tumours derived from the extra-adrenal paraganglia of the autonomic nervous system. They can be divided into two groups: sympathetic and parasympathetic tumours. Nearly all head and neck paragangliomas arise from the parasympathetic nervous system. These tumours can be sub-divided by the site of origin and, in most cases, this defines the name given, for example, carotid body tumour (CBT) or carotid paraganglioma, jugular paraganglioma, vagal paraganglioma or glomus intravagale. These tumours were previously known as chemodectomas or glomus tumours, but the term most commonly used is paraganglioma. Only a minority of paragangliomas (1-3\%) demonstrate actual clinical evidence of hyperfunctioning. ${ }^{1}$ Patients with clinical signs or symptoms indicating excessive catecholamine release are evaluated for the presence of a functional paraganglioma or multiple tumours. Multiple paragangliomas can occur in up to $40 \%$ of familial paragangliomas and in up to $10 \%$ of sporadic tumours. ${ }^{2}$
Paragangliomas of the head and neck generally present in middle age as asymptomatic, non-functional, spaceoccupying lesions. Having higher occurrence in women, however, tumours of extra-adrenal origin arising outside the head and neck more commonly occur in men. ${ }^{3}$ The majority are benign; however, malignant behaviour has been noted in approximately $4 \%$ of jugulotympanic tumours, $6 \%$ carotid body and $16 \%$ vagal paragangliomas. ${ }^{4}$ Paragangliomas, in general, exhibit a slow rate of growth with the potential to remain stable and, therefore, clinically silent over many years. Some papers have suggested that tumours that have been followed up by interval scanning show an increase in size of less than $5 \mathrm{~mm}$ per year. ${ }^{5}$

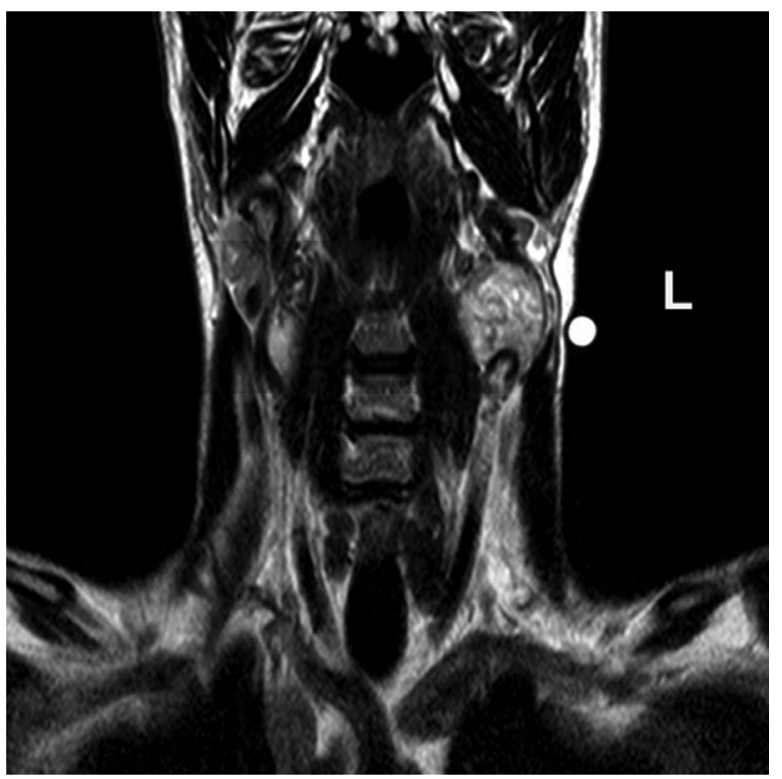

Figure 1 Bilateral enhancing lesions $-4 \mathrm{~cm} \times 3 \mathrm{~cm}$ on the left side and $2.6 \mathrm{~cm} \times 2 \mathrm{~cm}$ at the level of the carotid bifurcation and $5 \mathrm{~cm} \times 2.6 \mathrm{~cm}$ at the jugular bulb on the right side. 


\section{BMJ Case Reports}

To investigate for suspected paraganglioma a detailed history, focusing on a family history of any surgery for head and neck tumours, should be taken. MRI represents the most important imaging technique for evaluation and diagnosis of head and neck paragangliomas. This modality provides evaluation of the tumour in relation to surrounding soft tissue, vascular structures and highlights its characteristic vascular appearance. $^{6}$

Definitive treatment for head and neck paraganglioma is dependent on the following: biologic activity of the tumour, patient age, co-morbidities and potential morbidity. Unless catecholamine secretion is noticed, urgent treatment is not necessary. The main treatment modalities for paraganglioma are surgery and radiotherapy. Surgical outcome is measured by tumour resection without recurrence, whereas radiotherapy measures treatment efficiency by the absence of tumour growth, assessed by interval MRI. The slow growth of these tumours, essentially in the absence of symptoms, may negate the need for any active intervention other than regular observation and documentation of growth. ${ }^{7}$ A multi-disciplinary team approach is recommended for the course of treatment. ${ }^{8}$ For the patient described in the scenario, it was deemed that the best course of treatment would be interval scans. The patient was asymptomatic and refused surgery, but was made aware of any symptoms that should raise alarm and warrant immediate admission to the hospital.

Complications of paraganglioma surgery are determined by the site of the tumour. The larger the tumour, the more likely lower cranial palsies are. Some patients may need no treatment if they are older with asymptomatic tumours. Recent advances in skull base surgery, imaging and genetics have changed the diagnosis and treatment of paragangliomas. Genetic screening will eventually allow for earlier detection of familial lesions, and therefore early treatment of small lesions, making the risks of surgery even lower. ${ }^{8}$

Paragangliomas of the head and neck are uncommon, slow-growing tumours of neuroendocrine origin arising from the parasympathetic nervous system. The vast majority are benign. There is a low malignancy rate which is primarily determined by metastasis, not by local invasion. The most common is the CBT. They are slightly more common in women. Once a paraganglioma is suspected, MRI is the modality of choice and they can be characterised by their classic appearance and relation to surrounding structures. Complications of paraganglioma surgery are determined by the location of the paraganglioma. Recent advances in skull base surgery, imaging and genetics have changed the diagnosis and treatment of paragangliomas.

Learning points

- Good history and examination is vital including a detailed family history.

- Appropriate use of imaging is essential to enable an accurate diagnosis.

- A multi-disciplinary team approach is essential in treatment planning.

\section{Competing interests None.}

Patient consent Obtained.

\section{REFERENCES}

1. Manolidis S, Shohet JA, Jackson CG, et al. Malignant glomus tumors. Laryngoscope 1999;109:30-4.

2. Bikhazi PH, Roeder E, Attaie A, et al. Familial paragangliomas: the emerging impact of molecular genetics on evaluation and management. Am J Otol 1999;20:639-43.

3. Lack EE. Paraganglia of the head and neck region. In: Rosai JM., ed. Atlas of Tumor Pathology: Tumors of the Adrenal Gland and Extra-adrenal Paraganglia. Washington, DC: Armed Forces Institute of Pathology, 1997:303-6.

4. Kahn LB. Vagal body tumor (nonchromaffin paraganglioma, chemodectoma, and carotid body-like tumor) with cervical node metastasis and familial association. Ultrastructural study and review. Cancer 1976;38:2367-77.

5. van der Mey AGL, Frijns JHM, Cornelisse CJ, et al. Does intervention improve the natural course of glomus tumors? A series of 108 patients seen in a 32-year period. Ann Otol Rhinol Laryngol 1992;101:635-42.

6. Olsen WL, Dillon WP, Kelly WM, et al. MR imaging of paragangliomas. AJR Am J Roentgenol 1987;148:201-4.

7. Jansen JC, van den Berg R, Kuiper A, et al. Estimation of growth rate in patients with head and neck paragangliomas influences the treatment proposal. Cancer 2000;88:12.

8. Pellitteria PK, Rinaldob A, Myssiorekc D, et al. Paragangliomas of the head and neck. Oral Oncol 2004;40:563-75.

Copyright 2012 BMJ Publishing Group. All rights reserved. For permission to reuse any of this content visit

http://group.bmj.com/group/rights-licensing/permissions.

BMJ Case Report Fellows may re-use this article for personal use and teaching without any further permission.

Please cite this article as follows (you will need to access the article online to obtain the date of publication).

Trivedi RY, Leong SC. Bilateral paraganglioma. BMJ Case Reports 2012;10.1136/bcr-01-2012-5639, Published XXX

Become a Fellow of BMJ Case Reports today and you can:

- Submit as many cases as you like

- Enjoy fast sympathetic peer review and rapid publication of accepted articles

- Access all the published articles

- Re-use any of the published material for personal use and teaching without further permission

For information on Institutional Fellowships contact consortiasales@bmjgroup.com

Visit casereports.bmj.com for more articles like this and to become a Fellow 